\title{
Prevalence of obsessive-compulsive disorder in Turkish university students and assessment of associated factors Elcin Yoldascan ${ }^{1}$, Yarkin Ozenli ${ }^{2}$, Oguz Kutlu ${ }^{3}$, Kenan Topal*4 and Ali Ihsan Bozkurt ${ }^{5}$
}

\begin{abstract}
Address: ${ }^{1}$ Department of Public Health, Faculty of Medicine, Cukurova University, Adana, Turkey, ${ }^{2}$ Department of Psychiatry, Faculty of Medicine, Baskent University, Ankara, Turkey, ${ }^{3}$ Department of Computer and Teaching Technology Education, Faculty of Education, Cukurova University, Adana, Turkey, ${ }^{4}$ Department of Family Medicine, Faculty of Medicine, Pamukkale University, Denizli, Turkey and ${ }^{5}$ Department of Public Health, Faculty of Medicine, Pamukkale University, Denizli, Turkey
\end{abstract}

Email: Elcin Yoldascan - eyoldascan@cu.edu.tr; Yarkin Ozenli - ozyarkin@gmail.com; Oguz Kutlu - okutlu@cu.edu.tr; Kenan Topal* - ktopal9@yahoo.com; Ali Ihsan Bozkurt - abozkurt@pau.edu.tr

* Corresponding author

Published: 6 July 2009

BMC Psychiatry 2009, 9:40 doi:10.1186/1471-244X-9-40
Received: 18 November 2008

Accepted: 6 July 2009

This article is available from: http://www.biomedcentral.com/I47I-244X/9/40

(C) 2009 Yoldascan et al; licensee BioMed Central Ltd.

This is an Open Access article distributed under the terms of the Creative Commons Attribution License (http://creativecommons.org/licenses/by/2.0), which permits unrestricted use, distribution, and reproduction in any medium, provided the original work is properly cited.

\begin{abstract}
Background: Many students who begin university at risky periods for OCD development cannot meet the new challenges successfully. They often seek help and apply to the university health center for psychiatric distress. We aimed to determine the prevalence and associated factors of Obsessive Compulsive Disorder (OCD) at students of the Cukurova University in this cross sectional study.

Methods: This study was performed in the Cukurova University Faculty of Education with a population of 5500 students; the representative sample size for detecting the OCD prevalence was calculated to be 800 . After collecting sociodemographic data, we questioned the students for associated factors of OCD. The General Health Questionnaire-I2 (GHQ-I2) and Composite International Diagnostic Interview (CIDI, Section K) were used for psychiatric evaluation. Logistic regression analysis was performed to evaluate the linkage between $O C D$ and associated factors.

Results: A total of 804 university students were included in this study. The GHQ-12-positive students (24I students, 29.9\%) were interviewed using Section K of the CIDI (222 students, 27.6\%). OCD was diagnosed in $33(4.2 \%)$ students. The Logistic regression analysis of the data showed significant associations between OCD and male gender ( $\mathrm{p}: 0.036$ ), living on government dormitory ( $p: 0.003$ ), living on students' house/parental house ( $p: 0.006)$, having private room in the parental house ( $p: 0.055)$ and verbal abuse in the family ( $p: 0.006)$.

Conclusion: This study demonstrates a higher prevalence of OCD among a group of university students compared to other prevalence studies of OCD in Turkish society. Furthermore, our findings also suggest relationships between $O C D$ and sociodemographic factors, as well as other environmental stress factors.
\end{abstract}




\section{Background}

Obsession is defined as an unwanted, intrusive, improper, recurrent, and continual thought, impulse, and/or mental image. Compulsion refers to repetitious behavioral and/ or mental activities. Obsessions are usually perceived to be excessive and senseless by the external world and often cause considerable distress to their sufferers. Obsessivecompulsive events usually consume at least an hour of the sufferer's daytime period and cause embarrassment, especially in social, occupational, and other daily situations [1]. Studies investigating the lifelong prevalence of Obsessive-Compulsive Disorder (OCD) reveal concordant results. The prevalence ranges between $1.3 \%$ and $5.5 \%$, and OCD presents itself in $2.7 \%$ of the general population $[1,2]$. OCD is categorized under the group of anxiety disorders in DSM IV. Although other anxiety disorders in this category occur more frequently in men than women (female/male: $2 / 1$ ), the ratio of female/male prevalence is equal for OCD $[3,4]$. Genetics, temperament, stressful life events, and modeling parental behavior are all implicated in the etiology of the disorder. Clinical obsessions include the fear of dirt/germs, a yearning for symmetry/certainty, suspicion, sexuality, and a fixation on religion. Thus, compulsions often include rituals focused on cleansing, controlling, arranging, counting, touching, and collecting [5].

Although the age of onset varies, the most risky periods for OCD development are adolescence and young adulthood $[4,6]$. When they begin their new life in the university, those who cannot meet the new challenges successfully often seek help and apply to the university health center for psychiatric distress. They usually experience feelings of distress and hopelessness. These sentiments can translate into clinical depression, general anxiety, interpersonal relationship issues, behavioral disorders, and OCD $[7,8]$. However, very few studies in the literature address OCD among university students $[9,10]$. Moreover, there are no methodical surveys that investigate the epidemiology of OCD in university students.

Therefore, the goal of this study is to determine the lifelong prevalence and accompanying factors for OCD among university students. Even though the sample used is limited in its scope, we hope that this epidemiological study can serve as the basis for future cross-cultural comparisons.

\section{Methods}

\section{Subjects and Study Design}

This cross-sectional epidemiological study was conducted in the Cukurova University Faculty of Education Approval of the Ethics Committee of Cukurova University was obtained. A total of 5500 students were included in the study, and the representative sample size for OCD prevalence detection was calculated to be 800 ( $\alpha$ : 0.05, p: $2.5 \%$ and $\mathrm{d}: 2 \%)$. The study had two phases and was carried out from July 2006 to July 2007, with a maximum interval of 15 days, to avoid any changes in mental state. The first phase involved the application of a sociodemographic data form, which also included questions about environmental conditions. We randomly selected one of the nine departments of the Faculty of Education and visited this department during the first two days of the week. All of the students who attended class on these days were included in the study. The 12-item General Health Questionnaire (GHQ-12) was used to screen for psychiatric morbidity especially in primary care. There is evidence that the GHQ correlates well with other psychiatric screening tests. $[11,12]$ The validity and reliability of the Turkish version of the GHQ was previously approved. The reliability correlation, sensitivity, and specificity of the GHQ in this study were $0.78,0.74$, and 0.84 , respectively. $[13,14]$ GHQ-12-positive students were selected for the second phase and invited to the university health center. The students who respond to this invitation were interviewed using Section K of the CIDI (OCD K1-K21, Obsessive Compulsive Disorders Interview Criterion). The interviews administered by a public health specialist, by a psychiatrist and the general practitioners who were trained for CIDI and working in university health center. A qualitative assessment was subsequently performed by a psychiatrist to confirm the presence of OCD according to DSM IV criteria. $[15,16]$

\section{Instrument}

General Health Questionnaire (GHQ- I 2)

It is a self administered screening test for detecting poor mental health in the general population. This questionnaire has been widely used in many countries for detecting psychological morbidity since its development by Goldberg in 1970, subjects are asked to think about their health over the past few weeks and answer the questions accordingly. There were four response options for each item (better than usual, same as usual, less than usual, much less than usual). We used a bimodal response scale known as GHQ scoring; columns 1 and 2 are both scores 0 , and columns 3 and 4 are both scored 1 . This bimodal response scale is a simple method of scoring and eliminates errors due to "end-users" and "middle-users". [17] We take a cut off point 1/2 (maximum score 12) for indicating poorer psychological health. [18]

\section{Sociodemographic data form}

Part I consisted of personal data, such as age, sex, marital status, socioeconomic level, residential place, illness history, surgical history, and psychiatric treatment history. Part II included questions about family members, such as the number of rooms in the parental house, private room in the parental house, number of siblings, number of households, parental educational and socioeconomic lev- 
els, and history of verbal/physical abuse in the family. The answers of the students responded the items for verbal abuse were about belittling, screaming, threats, blaming or sarcasm in the family. And the items responded for physical abuse were about any act resulting with non accidental physical injury like beating, punching, biting and kicking and exposure to unreasonably severe corporal punishment or unjustifiable punishment in the family. [19]

\section{Composite International Diagnostic Interview (CIDI 2.I)}

This interview was developed by the World Health Organization. It is a comprehensive and fully-standardized diagnostic interview designed to assess mental disorders according to the definitions provided by the ICD-10 Diagnostic Criteria for Research and DSM IV [13]. It is composed of three parts: Part I include logical questions; Part II includes subject-oriented questions; Part III includes criterion-based questions. Psychiatric disorders can be diagnosed through "yes" or "no" answers to the questions in each diagnostic section. Responses are then evaluated according to a five-point scale: level 1) mental illness is not present; level 2) mental illness is present but not critical; level 3) mental illness is dependent on drug or substance abuse; level 4) mental illness is dependent on physical illness or injury; level 5) mental illness is present, and the cause is psychological. These scores can be converted into psychiatric diagnoses via specialized software. The CIDI can be applied by non-medical personnel after training. This interview requires approximately $70 \mathrm{~min}-$ utes under normal circumstances [20].

\section{Statistical Analyzes}

After descriptive statistics, were obtained the presence of OCD and relationship of the independent variables were analyzed by binary assessments. A Chi-square test was used for analyses. Then, logistic regression analysis (LRA) was performed to analyze the effect of these variables together. Before the LRA, the correlation coefficient between independent variables was calculated. According to these calculations, there was a high correlation between students' own economic situation and both parental economic situation as well as the education level of the father and mother (r: 0.70 and $\mathrm{r}$ : 0.61 respectively). Therefore, only students' own economic situation and the education level of the mother were included in the model.

The independent variables included in the LRA model were the class and department that the student was attending in the Faculty of Education, gender, marital status, students' own economic situation, residential place, number of siblings, number of households, number of rooms in the parental house, presence of a private room in the parental house, history of chronic illness, operation history, verbal and physical abuse in the family, history of verbal and physical abuse, and education level of the mother.

\section{Results}

A total of 804 students were included in this study. The GHQ-12-positive subjects (241 students, 29.9\%) were invited to the university health center. The students who responded (222 students, 27.6\%) were interviewed using Section K of the CIDI. OCD was diagnosed in 33 students and we found the prevalence of OCD (4.2\%) after excluding the nineteen students who did not respond to our invitation (Table 1). The non responding students have various reasons; eight had a physical illness, five had gone other universities, two drop out school, one had gone abroad and three of them reject to participate to the study.

The students' sociodemographic features are listed in Table 2. From the subjects, 510 (63.5\%) were female and 294 (36.5\%) were male. The parents of 288 (35.8\%) of the participants lived in Adana (the city in which the university is located); the remaining students' parents (64.2\%) dwelled in other Turkish cities. The education levels of the students' mothers were as follows: 160

Table I: Total population and results of screening.

\begin{tabular}{ll}
\hline Total population of the Cukurova University Faculty of Education students & 5500 \\
\hline The students screened with the GHQ-12 & 804 \\
\hline GHQ-12 positives & $241(29.9 \%)$ \\
\hline Students who did not respond for various reasons & $19(2.6 \%)$ \\
\hline Interviewed with Section K of the CIDI & $222(27.6 \%)$ \\
\hline Students who screened and interviewed & $785 *$ \\
\hline Prevalence of OCD & $33(4.2 \%)$ \\
\hline
\end{tabular}

*Students who did not interviewed were excluded. 
Table 2: Sociodemographic and characteristic features of study group and students diagnosed OCD.

\begin{tabular}{|c|c|c|c|c|c|}
\hline \multicolumn{2}{|c|}{ Sociodemographic and characteristic features } & \multicolumn{2}{|c|}{$\begin{array}{c}\text { Study Group } \\
n=804\end{array}$} & \multicolumn{2}{|c|}{$\begin{array}{c}\text { OCD Group } \\
n=33\end{array}$} \\
\hline & & $\mathbf{n}$ & $\%$ & $\mathbf{n}$ & $\%$ \\
\hline \multirow[t]{2}{*}{ Gender } & Male & 293 & 36.5 & 9 & 27.3 \\
\hline & Female & 510 & 63.5 & 24 & 72.7 \\
\hline \multirow[t]{2}{*}{ Marital Status } & Single & 781 & 97.6 & 31 & 93.9 \\
\hline & Married & 19 & 2.4 & 2 & 6.1 \\
\hline \multirow[t]{3}{*}{ Economic Situation } & Poor & 127 & 15.8 & 3 & 9.1 \\
\hline & Middle & 606 & 75.4 & 29 & 87.9 \\
\hline & Good & 68 & 8.5 & 1 & 3.0 \\
\hline \multirow[t]{4}{*}{ Residential Place } & Government dormitory & 276 & 32.1 & 9 & 27.3 \\
\hline & Private dormitory & 26 & 3.2 & 1 & 3.0 \\
\hline & Students' house/parental house & 499 & 62.3 & 20 & 60.6 \\
\hline & Other & 19 & 2.4 & 3 & 9.1 \\
\hline \multirow[t]{5}{*}{ Education level mother } & Illiterate & 160 & 20.1 & 10 & 30.3 \\
\hline & Literate & 59 & 7.4 & - & - \\
\hline & Primary school & 342 & 42.9 & II & 33.3 \\
\hline & Middle school & 150 & 18.7 & 8 & 24.2 \\
\hline & Higher Education & 86 & 10.7 & 4 & 12.1 \\
\hline \multirow[t]{2}{*}{ Private room in the parental house } & Exist & 448 & 55.7 & 24 & 72.7 \\
\hline & Not exist & 356 & 44.3 & 9 & 27.3 \\
\hline \multirow[t]{2}{*}{ Verbal abuse in the family, } & Exist & 55 & 6.9 & 8 & 24.2 \\
\hline & Not exist & 745 & 93.1 & 25 & 75.8 \\
\hline \multirow[t]{2}{*}{ Physical abuse in the family } & Exist & 21 & 2.6 & 2 & 6.1 \\
\hline & Not exist & 781 & 97.4 & 31 & 93.9 \\
\hline \multirow[t]{2}{*}{ Own history of verbal abuse } & Exist & 114 & 14.2 & 2 & 6.1 \\
\hline & Not exist & 689 & 85.7 & 31 & 93.9 \\
\hline \multirow[t]{2}{*}{ Own history of physical abuse } & Exist & 5 & 0.6 & - & - \\
\hline & Not exist & 799 & 99.4 & 33 & 100.0 \\
\hline
\end{tabular}


(19.9\%) were illiterate; 59 (7.3\%) were literate (i.e. they could read and write but had no formal education); 342 $(42.5 \%)$ were primary school graduates; 150 (18.7\%) were middle school graduates; $86(10.7 \%)$ were high school or university graduates.

Our results suggest relationships between OCD and female gender, living on government dormitory, living on students' house/parental house, having private room in the parental house and verbal abuse in the family $(\mathrm{OR}=$ $0.262, \mathrm{p}=0.036 ; \mathrm{OR}=0.035, \mathrm{p}=0.003 ; \mathrm{OR}=0.054, \mathrm{p}=$ $0.006 ; \mathrm{OR}=2.795, \mathrm{p}=0.055 ; \mathrm{OR}=9.203, \mathrm{p}=0.006$ respectively) (Table 3).

\section{Discussion}

The observed probability of psychiatric disorder in the university student cohort used in this study was $29.9 \%$, which is greater than the ratio found in the general Turkish population $(5-20 \%)$. At this point, we should consider the role of environmental stressors as well as family systems and genetic predisposition to OCD [21]. Many students who begin university at risky periods for OCD development cannot meet the new challenges successfully. Students who experience such stressors are more likely to display tendencies towards depression, general anxiety, behavioral disorders, and somatic complaints $[8,22]$.

We applied Section K of the CIDI to students who displayed a proclivity towards psychiatric disorders. OCD was diagnosed in 33 students $(4.2 \%$ of the cohort). Although the lifelong prevalence of OCD varies widely according to the literature, the rate is $2.5 \%$ in Turkish society [23]. Adolescents and young adults experience increased physiologic and reactive anxiety symptoms, and are thus more prone to anxiety disorders. Consequently, the illness rate in this population is around 20\% [1].

In preceding studies, the female/male OCD ratio was observed to be close to $1 / 1[3,4]$; in contrast with these findings, we observed a female/male ratio of $2.6 / 1$. However, we have to bear in mind that anxiety disorders are generally seen two to three times more frequently in young women than young men. Also, each sex exhibits different sensitivity levels to stress and anxiety disorders. Our findings, which illustrate that women displayed a higher response to stress than men, support the results of previous epidemiological studies conducted in seven different countries $[1,24]$. Similarly, Horwath and Weissman concluded from their cross-national epidemiological study that the lifetime prevalence of OCD is generally higher in women than men. For example, the female-tomale ratios are consistent for Korea (1.2), Puerto Rico (1.2), Edmonton (1.3), the United States (1.6), Taiwan (1.8), and in New Zealand (4.0). [25]
Although the previous clinical studies showed a correlation between high socioeconomic status and OCD $[26,27]$, Torres and Prince describe in their editorial comment epidemiological studies that have detected lower socioeconomic levels among OCD sufferers [28].

The relationship between childhood trauma, such as parental separation or child abuse, and anxiety disorders has been studied in recent years [29,30]. Animal studies have shown that negative experiences in childhood have a negative impact on the central nervous system and development [31,32]. Mathews et al. showed an association between emotional abuse, physical abuse and high levels of OCD symptoms in their study [33]. Lochner et al. found a significantly greater severity of childhood trauma in general and emotional neglect specifically, in the OCD groups compared to the controls [34]. We found significant positive correlations between the presence of familial verbal abuse and OCD but there was no association between physical abuse and OCD in our study. We used items for assessment verbal/physical abuse which was listed in the Diagnostic and Statistic Manual of Mental Disorders (DSM-IV-TR) under the heading of 'Other Conditions That May Be a Focus of Clinical Attention'. We thought that there can be a relation between physical abuse and OCD but our findings did not support this maybe because students display tendency not to disclose physical abuse.

There are some limitations that need to be acknowledged regarding the present study. The first limitation concerns about the method of the study. Our study was a cross-sectional epidemiological study but we know that prospective longitudinal studies are of great value for assessing psychiatric diseases. The second limitation is the co-morbid situations of the study population were not investigated and we did not ask about streptococcal infections directly although we asked about chronic illness and operation history.

\section{Conclusion}

Our study demonstrates a higher prevalence of OCD among a group of university students compared to other prevalence studies of OCD in Turkish society. These findings also suggest relationships between OCD and sociodemographic factors, as well as other environmental stressors. More methodological and longitudinal studies are needed to determine the prevalence and associated factors for OCD in different age groups from various layers of the population.

\section{Competing interests}

The authors declare that they have no competing interests. 
Table 3: The relationship between the independent variables and $O C D$.

\begin{tabular}{|c|c|c|c|c|}
\hline \multirow[t]{2}{*}{ Independent variables } & \multirow[t]{2}{*}{$\mathbf{p}$} & \multirow[t]{2}{*}{ OR } & \multicolumn{2}{|c|}{$95.0 \% \mathrm{Cl}$ for $\mathrm{OR}$} \\
\hline & & & Lower & Upper \\
\hline The Department Of The Student & 0.977 & & & \\
\hline Art Teaching & 0.897 & 10842.1 & 0.001 & 1.714 \\
\hline Primary School Teacher & 0.882 & 41953.6 & 0.001 & 6.949 \\
\hline Computer And Teaching Technology & 0.878 & 63265.1 & 0.001 & 1.033 \\
\hline Early Childhood Education & 0.997 & 1.5 & 0.001 & 1.403 \\
\hline Philosophy Group & 0.886 & 29958.1 & 0.001 & 4.720 \\
\hline German Language Teaching & 0.982 & 22.1 & 0.001 & 1.154 \\
\hline French Language Teaching & 0.991 & 3.269 & 0.001 & 2.448 \\
\hline English Language Teaching & 0.884 & 37112.6 & 0.001 & 6.153 \\
\hline Turkish Language Teaching & 0.890 & 21523.8 & 0.001 & 3.413 \\
\hline Science Knowledge & 0.867 & 170746.5 & 0.001 & 2.885 \\
\hline Social Sciences & 0.869 & | 39598.| & 0.001 & 2.333 \\
\hline Psychological Counseling And Guidance & 0.878 & 60296.3 & 0.001 & 9.806 \\
\hline The Class Of The Student & 0.654 & & & \\
\hline Class I & 0.287 & 7.390 & 0.186 & 29.391 \\
\hline Class 2 & 0.623 & 2.015 & 0.123 & 32.964 \\
\hline Class 3 & 0.457 & 1.864 & 0.361 & 9.625 \\
\hline Male Gender & 0.036 & 0.262 & 0.075 & 0.917 \\
\hline Being Single & 0.086 & 0.167 & 0.021 & 1.291 \\
\hline Economic Situation & 0.548 & & & \\
\hline Economic Situation Of The Family & 0.993 & 0.987 & 0.045 & 21.451 \\
\hline
\end{tabular}


Table 3: The relationship between the independent variables and OCD. (Continued)

\begin{tabular}{|c|c|c|c|c|}
\hline Economic Situation Of The Student & 0.560 & 2.197 & 0.156 & 30.987 \\
\hline Residential Place Of Student & 0.026 & & & \\
\hline Government Dormitory & 0.003 & 0.035 & 0.004 & 0.313 \\
\hline Private Dormitory & 0.189 & 0.114 & 0.004 & 2.907 \\
\hline Students' house/parental house & 0.006 & 0.054 & 0.007 & 0.435 \\
\hline Number Of Siblings & 0.640 & 1.073 & 0.797 & 1.445 \\
\hline Number Of Households & 0.142 & 0.798 & 0.590 & 1.078 \\
\hline Private Room In The Parental House & 0.055 & 2.795 & 0.978 & 7.992 \\
\hline Room Number Of The Parental House & 0.396 & 1.325 & 0.692 & 2.539 \\
\hline Illness History & 0.796 & 0.001 & 0.001 & 3588 \\
\hline Chronic Illness History & 0.066 & 3.565 & 0.918 & 13.850 \\
\hline Operation History & 0.114 & 0.250 & 0.045 & 1.397 \\
\hline Mental Disorder History & 0.432 & 2.387 & 0.273 & 20.891 \\
\hline Verbal Abuse In The Family & 0.006 & 9.203 & 1.882 & 45.006 \\
\hline Physical Abuse In The Family & 0.830 & 1.334 & 0.095 & 18.657 \\
\hline Own History Of Verbal Abuse & 0.076 & 0.156 & 0.020 & 1.216 \\
\hline Own History Physical Abuse & 0.969 & 0.001 & 0.001 & 5.596 \\
\hline Education Level Of Mother & 0.782 & & & \\
\hline Illiterate & 0.294 & 3.333 & 0.352 & 31.565 \\
\hline Literate & 0.870 & 0.001 & 0.001 & 3158 \\
\hline Primary School & 0.484 & 1.933 & 0.305 & 12.234 \\
\hline Middle School And Upper Level & 0.265 & 2.869 & 0.450 & 18.307 \\
\hline Constant & 0.871 & 0.001 & 0.186 & 293.919 \\
\hline
\end{tabular}

Abbreviations: OR: Odds Ratio; $\mathrm{Cl}$ : Confidence Interval 


\section{Authors' contributions}

EY Conceived of the study, performed the literature review, contributed to study design and data collection, and interviewed students. YO Contributed to study design and data collection, drafted the manuscript, interviewed students and performed the qualitative assessments. OK Contributed to study design, data collection and analysis. KT Contributed to the design and coordination of the study, drafted and edited the manuscript. AIB Contributed to study design and performed the statistical analysis. All authors read and approved the final manuscript.

\section{References}

I. Merikangas KR: Clinical Features of Anxiety Disorders. In Comprehensive Textbook of Psychiatry 8th edition. Edited by: Kaplan HI, Sadock BJ. Lippincott Williams \& Wilkins; 2004: I I04-I I 26.

2. Karno M, Golding JM, Sorenson SB, Burnam MA: The epidemiology of obsessive compulsive disorder in five US communities. Arch Gen Psychiatry 1988, 45: 1094-1099.

3. Tynes LL, White K, Steketee GS: Toward a new nosology of obsessive compulsive disorder. Comp Psychiatry 1990 31:465-480

4. Rasmussen SA, Eisen JL: The epidemiology and clinical features of obsessive compulsive disorder. Psych Clin N Amer 1992, 1 5:743-758.

5. Karamustafalıoglu KO: Obsessive compulsive disorder. Galenos Monthly Medical Journal 2006, 9:53-66

6. Noshirvani HF, Kasvikis Y, Marks IM, Tsakiris F, Monteiro WO: Gender divergent aetiological factors in obsessive compulsive disorder. Br J Psyciatry 1991, 158:260-263.

7. Dökmen Ü: A longitudinal psychological drama study in Ankara University Faculty of Education Sciences School Guidance Center. Psychological Guidance and Counseling Meeting in Higher Education Conference. 20-28 May 1987, Ankara .

8. Koç M, Polat $U$ : The mental health of the university students. International Human Sciences Journal 2006, 2: I-22.

9. McLaren S, Crowe SF: The contribution of perceived control of stressful life events and thought suppression to the symptoms of obsessive-compulsive disorder in both non-clinical and clinical samples. A Anxiety Disord 2003, 17:389-403.

10. Abdel-Khalek AM, Lester D: Obsession-compulsion in college students in the United States and Kuwait. Psychol Rep 1999, 85:799-800.

II. Goldberg DP: The detection of psychiatric illness by questionnaire. Oxford University Press; London; 1972.

12. Goldberg DP, Rickels K, Downing R, Hesbacher P: A comparison of two Psychiatric screening tests. British Journal of Psychiatry | 976, | 29:6|-67.

13. Kılıç C: The reliability and validity study of General Health Questionnaire. Turkish Psychiatry Journal 1996, 7:3-9.

14. Kılıc C, Rezaki M, Rezaki B, Kaplan I, Ozgen G, Sağduyu A Oztürk MO: General Health Questionnaire (GHQ-12 \& GHQ-28): psychometric properties and factor structure of the scales in a Turkish primary care sample. Soc Psychiatry Psychiatr Epidemiol 1997, 32:327-33।.

15. Witchen HU, Robins LN, Cottler LB, Janca A: Cross-cultural feasibility, reliability and sources of variance of the Composite International Diagnostic Interview (CIDI). BrJ Psychiatry I99I, 159:645-53-658.

16. Wittchen HU: Reliability and validity studies of WHO-Composite International Diagnostic Interview (CIDI): a critical review. J Psychiatr Res 1994, 28:57-84.

17. Barton J, Spelten E, Totterdell P, Smith L, Folkard S, Costa G: The Standard Shiftwork Index: A battery of questionnaires for assessing shiftwork-related problems. Work and Stress 1995 9:4-30.

18. Goldberg DP, Gater R, Sartorlus N, Ustun Tb, Piccinellı M, Gureje $\mathrm{O}$, Rutter C: The validity of two versions of the GHQ in the WHO study of mental illness in general health care. Psychological Medicine 1997, 27:191-197.
19. Sadock BJ, Kaplan HI, Sadock VA: Kaplan \& Sadock's synopsis of psychiatry: behavioral sciences/clinical psychiatry. 10th edition. Lippincott Williams \& Wilkins, Philadelphia; 2007:I 338 - I340.

20. Composite International Diagnostic Interview 2.I. The collaboration center of DSO, Psychiatry Department, University of Hacettepe Publishing No: 2, Ankara 1997.

21. Grados MA: Obsessive-compulsive disorder after traumatic brain injury. Int Rev Psychiatr 2003, 15:350-358.

22. Ultanir $E$ : The necessity of the opening psychological counseling and guiding center in newly founded universities. $A$ Journal of Contemporary Education 1996, 220:10-14.

23. Sahin AR: Obsessive compulsive disorder. In Psikiyatri Temel Kitabı (Basic Book of Psychiatry) Edited by: Güleç C, Köroğlu E. Press Union of Physicians, Ankara; 1997:493-504.

24. Nelson E, Rice J: Stability of diagnosis of obsessive compulsive disorder in the epidemiologic catchment area study. Am J Psiychiatry 1997, 154:826-83 [http://ajp.psychiatryonline.org/cgi/reprint/ 154/6/826].

25. Horwath E, Weissman MM: The epidemiology and crossnational presentation of obsessive-compulsive disorder. Psychiatr Clin North Am 2000, 23(3):493-507.

26. Akhtar S, Wig NN, Varma VK, Pershad D, Verma SK: A phenomenological analysis of symptoms in obsessive compulsive neurosis. Br J Psychiatry 1975, 127:342-348.

27. Maj M, Sartorius M: Etiology of obsessive compulsive disorder. In Obsessive Compulsive Disorder (WPA Series evidence and experience in Psychiatry) Volume 4. Edited by: Maj M, Sartorius M, Okasha A, Zohar J. Jonh Wiley \& Sons Ltd Press, NewYork; 1999:50-67.

28. Torres AR, Prince MJ: The importance of epidemiological studies on obsessive compulsive disorder. Rev Bras Psiquiatr 2004, 26: $14|-| 42$

29. Rasmussen SA, Tsuang MT: Clinical characteristics and family history in DSM III obsessive-compulsive disorder. Am J Psychiatry 1986, 143:317-322.

30. Honjo S, Hirano C, Murase S, Kaneko T, Sugiyama T, Ohtaka K, Aoyama T, Takei Y, Inoko K, Wakabayashi S: Obsessive-compulsive symptoms in childhood and adolescence. Acta Psychiatr Scand 1989, 80:83-91.

3I. Finn DA, Rutledge-Gorman MT, Crabbe JC: Genetic animal models of anxiety. Neurogenetics 2003, 4: I09-II 2

32. Groenink L, van Bogaert MJ, Gugten J van der, Oosting RS, Olivier B: 5-HTIA receptor and 5-HTIB receptor knockout mice in stress and anxiety paradigms. Behav Pharmacol 2003, 14:369-373.

33. Mathews CA, Kaur N, Stein MB: Childhood trauma and obsessive-compulsive symptoms. Depression and Anxiety 2002, 25:742-75।.

34. Lochner C, du Toit PL, Zungu-Dirwayi N, Marais A, Kradenburg J, Seedat S, Niehaus DJ, Stein DJ: Childhood trauma in obsessivecompulsive disorder, trichotillomania, and controls. Depression and Anxiety 2002, 15:66-68.

\section{Pre-publication history}

The pre-publication history for this paper can be accessed here:

http://www.biomedcentral.com/1471-244X/9/40/pre pub 